were classified as NGT, 47 as IGT or IFG, and 14 as Type II diabetes. To detect the $-174 G / C$ polymorphism, we carried out a PCR-RFLP with Sfa NI restriction enzyme and primers or a direct sequence [5]. Informed consent was obtained from all subjects.

We did not detect the $-174 C / C$ or $G / C$ allele in men with Type II diabetes nor in the control men and all 388 subjects were $-174 G$ homozygotes. Thus, in Japanese men, the $-174 C /$ $C$ and $G / C$ alleles were very rare, and this polymorphism was not a major contributing factor to hyperlipidaemia, insulin resistance, or Type II diabetes.

The frequency of the $-174 \mathrm{C}$ allele varies among races; in Caucasian subjects, $0.40 \sim 0.45$; in Gujarati Indians, 0.15; and in Afro-Caribbean subjects, 0.05 [4-8]. In Gujarati Indians and Afro-Caribbeans, no association was found between the $-174 G / C$ polymorphism and plasma IL- 6 concentration [4]. In another investigation of Hela cells, contrary to the earlier report, basal and IL-1-induced IL-6 transcriptions of the $-174 \mathrm{C}$ allele were the same as the $-174 G$ allele, and in ECV304 cells IL-1 did not increase IL-6 transcriptions in either allele [7]. In observations of Caucasian patients with abdominal aortic aneurysms, plasma IL-6 concentrations were the highest, intermediate, and lowest in the $-174 C / C, G / C$, and $G / G$ alleles, respectively [8]. Thus, in Caucasian subjects, the effects of this polymorphism on IL-6 secretion remain controversial, requiring further studies to clarify the relation between the $-174 G$ / $C$ polymorphism and insulin sensitivity and hyperlipidaemia in Caucasian subjects.

In conclusion, the $-174 G / C$ polymorphism in the $I L-6$ gene is very rare and does not contribute substantially to hyperlipidaemia, insulin resistance, or Type II diabetes in Japanese men.

T.Hayakawa, T.Takamura, A.Hisada, T. Abe, G. Nomura, K. Kobayashi

\section{Glucokinase gene mutations are not a common cause of permanent neonatal diabetes in France}

To the Editor: Neonatal diabetes mellitus (NDM), defined as insulin-requiring hyperglycaemia within the first months of life, is a rare entity with an estimated incidence of 1 in 400000 neonate infants [1]. In about half of the neonates, diabetes is transient and usually goes into remission within the first 6 months of life, while the rest of patients have a permanent form of diabetes. In addition, in a large number of patients with transient neonatal diabetes mellitus (TNDM), diabetes reappears later in life [2]. The association between TNDM and abnormalities of chromosome 6 , either paternal isodisomy or partial trisomy with duplication of the paternal genome in the $6 \mathrm{q} 24$ region or methylation defect in the same region, has raised the possibility that an imprinted, paternally expressed gene is involved in its pathogenesis [3, 4].

A recent study has described two patients in whom complete deficiency of the glycolytic enzyme glucokinase (GCK), a key regulator of glucose metabolism in pancreatic beta cells that couples extracellular glucose to insulin secretion, caused permanent neonatal-onset diabetes mellitus (PNDM) [5]. One patient was homozygous for an M210K mutation which was inherited from each parent heterozygous for this mutation in a context of consanguinity and cosegregated with diabetes

\section{References}

1. Yudkin JS, Kumari M, Humphries SE, Mohamed-Ali V (2000) Inflammation, obesity, stress and coronary heart disease: is interleukin-6 the link? Atherosclerosis 148: 209-214

2. Pickup JC, Mattock MB, Chusney GD, Burt D (1997) NIDDM as a disease of the innate immune system: association of acute-phase reactants and interleukin- 6 with metabolic syndrome X. Diabetologia 40: 1286-1292

3. Suzuki D, Miyazaki M, Naka R et al. (1995) In situ hybridization of interleukin 6 in diabetic nephropathy. Diabetes 44: $1233-1238$

4. Fishman D, Faulds G, Jeffery R et al. (1998) The effect of novel polymorphisms in the interleukin-6 (IL-6) gene on IL-6 transcription and plasma IL-6 levels, and an association with systemic-onset juvenile chronic arthritis. J Clin Invest 102: 1369-1376

5. Fernández-Real JM, Broch M, Vendrell J et al. (2000) Interleukin-6 gene polymorphism and insulin sensitivity. Diabetes 49: $517-520$

6. Fernández-Real JM, Broch M, Vendrell J, Richart C, Richart W (2000) Interleukin-6 gene polymorphism and lipid abnormalities in healthy subjects. J Clin Endocrinol Metab 85: 1334-1339

7. Terry CF, Loukaci V, Green FR (2000) Cooperative influence of genetic polymorphisms on interleukin 6 transcriptional regulation. J Biol Chem 275: 18138-18144

8. Jones KG, Brull DJ, Brown LC et al. (2001) Interleukin-6 (IL-6) and the prognosis of abdominal aortic aneurysms. Circulation 103: 2260-2265

T. Hayakawa, Department of Endocrinology and Metabolism, Kanazawa University Graduate School of Medical Science, 13-1 Takara-machi, Kanazawa, Ishikawa 920-8641, Japan, email: hayakawa@medf.m.kanazawa-u.ac.jp

or hyperglycaemia in other family members; the other was homozygous for a T228M mutation that has been found previously in an heterozygous state in a family with glucokinase-related MODY [6]. Both patients showed a total absence of basal insulin release, confirming the key role for glucokinase in controlling basal insulin as well as glucose-induced insulin secretion.

To look for similar genetic defects in the French population, we screened for mutation all the 10 coding exons of the GCK gene, including exons $1 \mathrm{~b}$ and $1 \mathrm{c}$ [7], and the $630 \mathrm{bp}$ minimal promoter region in 11 probands who presented with diabetes mellitus in the first months of life (Table 1). The parents of all of the participating infants gave their informed consent and our investigations were carried out in accordance with the Declaration of Helsinki as revised in 1996. One patient (HB) had TNDM and was off insulin therapy at the time of the examination. His fasting blood glucose concentration was normal but his insulin secretion elicited by intravenous glucose infusion was totally blunted, which might therefore involve a beta-cell defect in glucose sensing as described in $G C K$ mutation carriers with MODY2. No glucose intolerance was present in the first degree family members. The 10 other children have PNDM as they were still on insulin therapy after 18 months of age. They were all full-term babies. Five of those had severe intra-uterine growth retardation (birth weight $\leq 5^{\text {th }}$ percentile). Age at presentation of diabetes varied from 3 days of life to 127 days. Only three of those had a first degree relative with glucose intolerance. None of the included subjects had abnormalities of the chromosome 6q24 region. None 
Table 1. Clinical, biological and therapeutic data of the patients studied

\begin{tabular}{|c|c|c|c|c|c|c|}
\hline Participant & $\begin{array}{l}\text { Birth weight }(\mathrm{g}) \\
\text { [percentile] }\end{array}$ & $\begin{array}{l}\text { Gestational age } \\
\text { (weeks) }\end{array}$ & $\begin{array}{l}\text { Age at diagnosis } \\
\text { of hyperglycaemia } \\
\text { (days) }\end{array}$ & $\begin{array}{l}\text { Glycaemia/insulin- } \\
\text { aemia mmol per } \\
\text { 1/ UI/l At diagnosis }\end{array}$ & $\begin{array}{l}\text { Initial insulin } \\
\text { dose Units/kg/day }\end{array}$ & $\begin{array}{l}\text { Glucose } \\
\text { intolerance } \\
\text { in the parents }\end{array}$ \\
\hline $\mathrm{HB}$ & $1200[<5]$ & 33 & 2 & $11 /<3$ & 0.46 transient & No \\
\hline PG & $2610[<5]$ & 41 & 41 & $36 / 12$ & 1.1 & No \\
\hline SL & $2780[<5]$ & 41 & 6 & $22.2 /$ not determined & 1.2 & Yes \\
\hline TK & $2900[8]$ & 40 & 60 & unknown & unknown & No \\
\hline SK & $2590[5]$ & 39 & 127 & 44.5 /undetectable & 4.8 ketoacidosis & No \\
\hline ST & $3600[60]$ & full term & 90 & 17.2 / not determined & 1.49 & Yes \\
\hline $\mathrm{JR}$ & $2110[<5]$ & 38 & 3 & $16 / 3.7$ & unknown & No \\
\hline $\mathrm{CB}$ & $3150[25]$ & full term & 89 & $22 /$ not determined & 1.15 & Yes \\
\hline ML & $3000[30]$ & 38.5 & 95 & 55 /undetectable & 2.4 ketoacidosis & No \\
\hline EP & $3065[8]$ & 41 & 123 & $28.6 / 1.48$ & 2 & No \\
\hline $\mathrm{AB}$ & $2400[<5]$ & 41 & 37 & $68 /<3$ & 1.2 & No \\
\hline
\end{tabular}

of the subjects had evidence of autoimmune diabetes mellitus as either autoantibodies against pancreatic islets cells were negative and/or HLA haplotypes were not of those at risk for Type I (insulin-dependent) diabetes mellitus.

The exons, flanking introns and promoter region of the gene encoding GCK were screened by direct sequencing of PCR amplified genomic DNA, and by using the denaturing high-performance liquid chromatography (DHPLC) technique, which discriminates homoduplices and heteroduplices in PCR products [8]. None of the 11 subjects that we analysed showed any mutations in the gene encoding the beta-cell GCK.

In conclusion, $G C K$ mutations are not a common cause of PNDM in France. We suggest that such a genetic defect should be searched for in case of permanent neonatal diabetes with an history of glucose intolerance in first degree relatives, especially when consanguinity is suspected.

M. Vaxillaire, C. Samson, H. Cavé, C. Metz, P. Froguel, M. Polak

\section{References}

1. Shield JP, Gardner RJ, Wadsworth EJK et al. (1997) Aetiopathology and genetic basis of neonatal diabetes. Arch Dis Child Fetal Neonatal Ed 76: F39-F42

2. Temple IK, Gardner RJ, Mackay DJ, Barber JC, Robinson DO, Shield JP (2000) Transient neonatal diabetes: widening the understanding of the etiopathogenesis of diabetes. Diabetes 49: 1359-1366

3. Cave H, Polak M, Drunat S, Denamur E, Czernichow P (2000) Refinement of the $6 \mathrm{q}$ chromosomal region implicated in transient neonatal diabetes. Diabetes 49: 108-113

\section{Detecting glucose intolerance after gestational diabetes: inadequacy of fasting glucose alone and risk associated with gestational diabetes and second trimester waist-hip ratio}

To the Editor: Women with gestational diabetes are at an increased risk for future alterations in glucose tolerance [1] but when diagnosed by the World Health Organization criteria [2] the magnitude of this risk has been little investigated. The pur-
4. Arima T, Drewell RA, Arney KL et al. (2001) A conserved imprinting control region at the HYMAI/ZAC domain is implicated in transient neonatal diabetes mellitus. Hum Mol Genet 10: 1475-1483

5. Njolstad PR, Sovik O, Cuesta-Munoz A et al. (2001) Neonatal diabetes mellitus due to complete glucokinase deficiency. New Eng J Med 344: 1588-1592

6. Velho G, Blanche H, Vaxillaire M et al. (1997) Identification of 14 new glucokinase mutations and description of the clinical profile of 42 MODY-2 families. Diabetologia 40: 217-224

7. Stoffel M, Froguel P, Takeda J et al. (1992) Human glucokinase gene: isolation, characterization, and identification of two missense mutations linked to early-onset non-insulindependent (type 2) diabetes mellitus. Proc Nat Acad Sci 89: 7698-7702

8. Boutin P, Vasseur F, Samson C, Wahl C, Froguel P (2001) Routine mutation screening of HNF-1alpha and GCK genes in MODY diagnosis: how effective are the techniques of DHPLC and direct sequencing used in combination? Diabetologia 44: 775-778

Corresponding author: M. Vaxillaire, CNRS UPRESA 8090, Institut de Biologie et Institut Pasteur de Lille, 1 rue du Pr Calmette, B.P. 245, 59019 Lille Cedex, France, e-mail: martine.vaxillaire@pasteur-lille.fr

Abbreviations: TNDM, Transient neonatal diabetes mellitus; GCK, glucokinase; PNDM, permanent neonatal-onset diabetes mellitus; NDM, neonatal diabetes mellitus

pose of this report is to evaluate glucose alterations and associated risk factors 4 to 8 years after pregnancy in a sub-sample of the Brazilian Study of Gestational Diabetes.

All patients with gestational diabetes $(n=159)$ and a randomly assigned sample of control subjects $(n=334)$ from a large cohort in Brazil [3] were recruited in the cities of Fortaleza and Porto Alegre. The glucose status was re-evaluated $5.7 \pm 0.9$ years after the index pregnancy. In total, 117 women with gestational diabetes and 167 control subjects answered a standard questionnaire; weight, height and waist circumferences were measured and a $2 \mathrm{~h}$ 75-g OGTT was carried out [4]. The study protocol was approved by the ethics committees at the Clinical Hospital of Porto Alegre (Hospital de Clinicas de 